\title{
Liquid-Crystalline Phase Transition in Organophosphazenes
}

\author{
Keiichi Moriya, ${ }^{1 *}$ Toshiya Suzuki, ${ }^{1}$ Yasuyuki Kawanishi, ${ }^{1}$ Tsuyoshi Masuda, ${ }^{1}$ \\ Hiroshi Mizusaki, ${ }^{1}$ Shigekazu Nakagawa, ${ }^{1}$ Hiroshi lkematsu, ${ }^{1}$ Katsuyuki \\ Mizuno, ${ }^{1}$ Shinichi Yano $^{1}$ and Meisetsu Kajiwara ${ }^{2}$ \\ ${ }^{1}$ Department of Chemistry, Faculty of Engineering, Gifu University, Yanagido, Gifu 501-1193, Japan \\ ${ }^{2}$ School of Dentistry, Aichigakuin University, Kusumoto-cho, 1-100, Chikusa-ku, 464-8586, Japan
}

\begin{abstract}
Organophosphazenes with a similar mesogenic moiety were prepared and their mesogenicity was studied by differential scanning calorinetry (DSC) measurements and polarizing microsope observations. In cyclotriphosphazenes with alkoxybiphenyl and Schiff base moieties, mesomorphic phase transitions were observed, but no mesomorphic phase was observed for the corresponding cyclotetraphosphazenes. In polyphosphazenes with an alkoxybiphenyl moiety, no mesomorphic phase was observed. The molecular structure of cyclotriphosphazenes facilitated the formation of a mesomorphic layer structure; in contrast, the formation of a mesomorphic layer structure did not occur in cyclotetraphosphazenes and polyphosphazenes, even though they bore a similar mesogenic moiety. Moreover, in cyclotriphosphazenes with an optically active alkoxybiphenyl group, a smectic $\mathrm{C}^{*}$ phase was observed. The spontaneous polarization of the compound was $-190 \mu \mathrm{C} \mathrm{m}^{-2}$ at $436 \mathrm{~K}$ in $25 \mu$ in cell using the triangular-wave method. (C) 1998 John Wiley \& Sons, Ltd.
\end{abstract}

Keywords: organophosphazenes; liquid crystals; phase transition

Received 21 October 1997; accepted 11 February 1998

\section{INTRODUCTION}

Much attention has been focused on organophosphazenes because they consist of inorganic backbones as well as organic side-chains. Thus they can be considered as hybrids of organic and inorganic compounds and their properties are a combination

* Correspondence to: K. Moriya, Department of Chemistry, Faculty of Engineering, Gifu University, Yanagido, Gifu 501-1193, Japan. of both. The functional properties of polymers and trimers consisting of organophosphazenes have been studied extensively. ${ }^{1-5}$

Several liquid-crystalline organophosphazenes including polymers and trimers have been synthesized but their structural features seem to lie in the long alkyl-ether chains between the mesogenic side-groups and the phosphazene backbones. ${ }^{6-10}$ We considered that the direct introduction of aryloxy mesogenic side-groups into the organophosphazene backbones (the $\mathrm{P}=\mathrm{N}$ linkages) without any spacer could produce interesting properties because the movement of the mesogens is limited by the linkage between mesogenic side-chains and the organophosphazene backbones. Hence, we tried to introduce aryloxy mesogenic side-groups directly to the organophosphazene backbones without any spacer, and we studied their phase transition and mesogenicity using thermal, optical and spectroscopic methods to see how their mesogenicity would be changed in these multi-substituted phosphazene nuclei. These compounds make an interesting group of liquid crystals because of their peculiar molecular shape. ${ }^{11-18}$

In this paper, we describe the liquid-crystalline phase transition of cyclotriphosphazenes, cyclotetraphosphazenes and polyphosphazene bearing similar mesogenic groups. We also describe the relationship between molecular structure and mesogenicity. The chemical structures of the organophosphazenes studied are shown in Fig. 1.

\section{EXPERIMENTAL}

Reactions were monitored by thin-layer chromatography (TLC) using Merck $60 \mathrm{~F}_{254}$ precoated silicagel plates (thickness $0.25 \mathrm{~mm}$ ). Silica gel (Wakogel C-200) and reagent-grade solvents were used for column chromatography. All substrate analogues 
<smiles>[2H]P1([2H])=NP([2H])([O])=NP([O])(O)=N1</smiles>

(a)

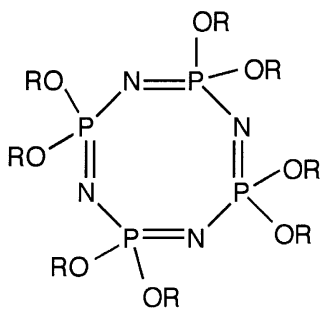

(b)<smiles>[R]OP(C)(=N)O[R]</smiles>

(c)

$$
\mathrm{R}=\mathrm{C}_{6} \mathrm{H}_{4} \mathrm{C}_{6} \mathrm{H}_{4} \mathrm{OC}_{8} \mathrm{H}_{17}, \mathrm{C}_{6} \mathrm{H}_{4} \mathrm{CH}=\mathrm{NC}_{6} \mathrm{H}_{4} \mathrm{OC}_{7} \mathrm{H}_{15} \text {, }
$$
$\mathrm{C}_{6} \mathrm{H}_{4} \mathrm{C}_{6} \mathrm{H}_{4} \mathrm{OC}_{5} \mathrm{H}_{10} \mathrm{CH}\left(\mathrm{CH}_{3}\right) \mathrm{C}_{2} \mathrm{H}_{5}$

Figure 1 Chemical structure of organophosphazene (a) trimer, (b) tetramer and (c) polymer.

were purified chromatographically to homogeneity by TLC analysis and purity was confirmed by ${ }^{1} \mathrm{H}$ and ${ }^{31} \mathrm{P}$ NMR. The solvent was distilled before use. All solvents are reagent-grade unless otherwise stated, and anhydrous solvents were dried immediately before use.

\section{Synthesis of organophosphazenes with an alkoxybiphenyl moiety}

4-Hydroxy-(4'-octyloxy)biphenyl (HOB) was prepared from 4,4'-dihydroxybiphenyl (80 g, $0.43 \mathrm{~mol}), 1$-bromo-octane $(55.2 \mathrm{~g}, 0.29 \mathrm{~mol})$ and $\mathrm{KOH}(24.2 \mathrm{~g}, 0.43 \mathrm{~mol})$ in ethanol $(1200 \mathrm{ml})$ under reflux for $6 \mathrm{~h}$. The crystals obtained were recrystallized from toluene and ethanol, once and twice respectively. The purity was examined by TLC (silica gel, chloroform).

Hexakis [4'-(4-octyloxy)biphenoxy]cyclotriphosphazene (HOCP) was prepared by the reaction of hexachlorocyclotriphosphazene (HCCP) (supplied by Nihon Fine Chemicals Co., Ltd) (2.6 g, $7 \mathrm{mmol}), \mathrm{HOB}(20 \mathrm{~g}, 67 \mathrm{mmol})$ and sodium hydride $(1.6 \mathrm{~g}, 67 \mathrm{mmol})$ in dioxane solution $(200 \mathrm{ml})$ in the presence of tetra-n-butylammonium bromide $(1.3 \mathrm{~g}, 4 \mathrm{mmol}){ }^{17}$ After the solution had been refluxed for $24 \mathrm{~h}$, the crude products were purified using column chromatography (chloroform) and then recrystallized from 1:1 tetrahydefuran (THF)/ cyclohexane. The purified HOCP crystals were characterized by TLC (7:3, chloroform/hexane), IR, ${ }^{1} \mathrm{H}$ and ${ }^{31} \mathrm{P}$ NMR, and elemental analyses. The analytical results for HOCP were as follows: m.p. $440 \mathrm{~K}$, clearing point (c.p.) $457 \mathrm{~K}$; IR (KBr) 2930, 1608, 1240, 1170, 980, $760 \mathrm{~cm}^{-1}$; ${ }^{1} \mathrm{H}$ NMR $\left(\mathrm{CDCl}_{3}\right) \delta 0.9(\mathrm{t}, 6.8 \mathrm{~Hz}, 6 H), 1.3-1.8(\mathrm{~m}, 13 H)$, $4.4(\mathrm{~m}, 1 H), 6.8(\mathrm{~d}, 8.4 \mathrm{~Hz}, 2 H), 6.9(\mathrm{~d}, 8.5 \mathrm{~Hz}, 2 H)$, $7.2(\mathrm{~d}, 8.4 \mathrm{~Hz}, 2 H), 7.3(\mathrm{~d}, 8.5 \mathrm{~Hz}, 2 H) ;{ }^{31} \mathrm{P}$ NMR $\delta$ 10.6(s). Analysis: Calcd for $\mathrm{C}_{120} \mathrm{H}_{150} \mathrm{~N}_{3} \mathrm{O}_{12} \mathrm{P}_{3}$ : C, $75.09 ; \mathrm{H}, 7.88 ; \mathrm{N}, 2.19$; found: C, 74.93; H, 7.96; N, $2.23 \%$.

The synthesis of 4-hydroxy (4'-octyloxy)biphenyl (HOB) was described above. Octakis[4'-(4-octyloxy)biphenoxy]cyclotetraphosphazen (OOCP) was prepared by the reaction of octachlorocyclotetraphosphazene $(3.48 \mathrm{~g}, 7.5 \mathrm{mmol})$ (supplied by Nihon Soda Co., Ltd), HOB (19.8 g, $60.0 \mathrm{mmol})$ and sodium hydride $(2.40 \mathrm{~g}$, $60.0 \mathrm{mmol}$ ) in the presence of tetra-n-butylammonium bromide $(1.93 \mathrm{~g}, 60 \mathrm{mmol})$ in dioxane $(200 \mathrm{ml})$ under reflux for $26 \mathrm{~h}$. The crude crystals obtained were purified by recrystallizing from 3:20 THF cyclohexane after column chromatography $\left(\mathrm{CHCl}_{3}\right)$. OOCP was confirmed to be thoroughly purified on the basis of NMR and IR spectra. The analytical results for OOCP were as follows: m.p. $411 \mathrm{~K}$; IR (KBr) 2925, 1607, 1493, 1244, 1169 , 966, $725 \mathrm{~cm}^{-1}$; ${ }^{1} \mathrm{H} \mathrm{NMR}\left(\mathrm{CDCl}_{3}\right) \delta 0.9(\mathrm{t}, 6.8 \mathrm{~Hz}$, $3 H), 1.30-1.83(\mathrm{~m}, 12 H), 3.96(\mathrm{t}, 7.3 \mathrm{~Hz}, 2 H), 6.82-$ $7.30(\mathrm{~m}, 8 H), 6.9(\mathrm{~d}, 8.5 \mathrm{~Hz}, 2 H), 7.2(\mathrm{~d}, 8.4 \mathrm{~Hz}$, $2 H), 7.3(\mathrm{~d}, 8.5 \mathrm{~Hz}, 2 H) ;{ }^{31} \mathrm{P}$ NMR $\delta-11.1(\mathrm{~s})$.

Polydichlorophosphazene (PDCP) was prepared from the ring-opening polymerization of hexachlorocyclotriphosphazene $(20 \mathrm{~g}, 58 \mathrm{mmol})$ using sulfur $(0.32 \mathrm{~g}, 10 \mathrm{mmol})$ as a catalyst at $270{ }^{\circ} \mathrm{C}$ for $3 \mathrm{~h}$ in an evacuated pyrex tube.

Poly $\{$ bis[4'-(4-octyloxy)biphenoxy]phosphazene (POP) was prepared by the substitution reaction of PDCP $(0.98 \mathrm{~g}, 8.5 \mathrm{mmol})$ and 4-hydroxy (4'-octyloxy)biphenyl (10.7 g, $35 \mathrm{mmol})$ and $\mathrm{NaH}$ $(0.84 \mathrm{~g}, 35 \mathrm{mmol})$ in the presence of tetra-nbutylammonium bromide $(1.1 \mathrm{~g}, 3.5 \mathrm{mmol})$ in THF $(50 \mathrm{ml})$ under reflux for $160 \mathrm{~h}$. The reaction was followed by ${ }^{31} \mathrm{P}$ NMR. The obtained polymers were extracted by Soxhlet apparatus using THF ethanol (1:1) solution after the THF solution of the 
polymer was reprecipitated into ethanol. The ${ }^{31} \mathrm{P}$ NMR showed a broad singlet around -14 ppm but the elemental analysis confirmed that only $66 \%$ of the side-chains were attached to the polyphosphazenes.

\section{Synthesis of organophosphazenes with a Schiff base moiety}

4-Heptyloxyacetanilide was synthesized from 4hydroxyacetanilide $(25 \mathrm{~g}, 0.16 \mathrm{~mol})$, bromoheptane $(28.5 \mathrm{~g}, 0.16 \mathrm{~mol})$ and $\mathrm{KOH}(11 \mathrm{~g}, 0.17 \mathrm{~mol})$ in ethanol $(200 \mathrm{ml})$ under reflux for $6 \mathrm{~h}$. The crude products obtained were recrystallized three times from 1:3 water ethanol mixed solvent. The purity of the sample was determined by TLC (ethyl acetate). 4-Heptyloxyaniline was synthesized from 4-heptyloxyacetanilide $(20 \mathrm{~g}, 83 \mathrm{mmol})$ and $\mathrm{KOH}(15 \mathrm{~g}$, $0.23 \mathrm{~mol})$ in ethanol $(200 \mathrm{ml})$ under reflux for $24 \mathrm{~h}$. After the reaction was finished, the solution was added to water $(50 \mathrm{ml})$. The crude products were extracted with benzene and then recrystallized four times from 3:1 water ethanol solution. The purity of the sample was recognized by TLC (ethyl acetate). Hexakis(4-formylphenoxy)cyclotriphosphazene was synthesized from 4-hydroxybenzaldehyde $(30.2 \mathrm{~g}, 0.25 \mathrm{~mol}), \mathrm{NaH}(6.0 \mathrm{~g}, 0.25 \mathrm{~mol})$ and hexachlorocyclotriphosphazene $(12.1 \mathrm{~g}, 34 \mathrm{mmol})$ in THF $(200 \mathrm{ml})$ under reflux for $2 \mathrm{~h}$. The crude products were recrystallized from hexane THF solution. The product was confirmed by TLC (ethyl acetate), ${ }^{1} \mathrm{H}$ and ${ }^{31} \mathrm{P}$ NMR

Hexakis $\left\{\left[4-\left[N-\left(4^{\prime}\right.\right.\right.\right.$-heptyloxyphenyl)iminomethyl]phenoxy] \} cyclotriphosphazene (HHICP) was prepared by the reaction of hexakis(4-formylphenoxy)cyclotriphosphazene $(1.06 \mathrm{~g}, 1.2 \mathrm{mmol})$ and 4-heptyloxyaniline $(2.48 \mathrm{~g}, 12 \mathrm{mmol})$ in benzene $(100 \mathrm{ml})$ under reflux for $6 \mathrm{~h}$. The crude products obtained were recrystallized three times from absolute THF after separation by filtration. The products were judged to be thoroughly purified by ${ }^{1} \mathrm{H}$ and ${ }^{31} \mathrm{P}$ NMR, and elemental analysis. The analytical results for HHICP were as follows. m.p. $463 \mathrm{~K}$, c.p. $515 \mathrm{~K}$; IR (KBr) 2933, 2858, 1626, 1604, 1578, 1251, 1219, 1161, $983 \mathrm{~cm}^{-1} ;{ }^{1} \mathrm{H}$ NMR $\left(\mathrm{CDCl}_{3}\right) \delta 1.1(\mathrm{t}, 7.3 \mathrm{~Hz}, 6 H), 1.3-1.8(\mathrm{~m}, 10 H), 3.9$ $(\mathrm{t}, 7.3 \mathrm{~Hz}, 2 H), 6.8(\mathrm{~d}, 8.8 \mathrm{~Hz}, 2 H), 7.0(\mathrm{~d}, 8.8 \mathrm{~Hz}$, $2 H), 7.1(\mathrm{~d}, 8.8 \mathrm{~Hz}, 2 H), 7.7(\mathrm{~d}, 8.45 \mathrm{~Hz}, 2 H), 8.4(\mathrm{~s}$, $1 H) ;{ }^{31} \mathrm{P}$ NMR $\delta$ 9.7(s). Analysis: Calcd for $\mathrm{C}_{120} \mathrm{H}_{144} \mathrm{~N}_{9} \mathrm{O}_{12} \mathrm{P}_{3}$ : C, 72.16; $\mathrm{H}, 7.27 ; \mathrm{N}, 6.31$; found: $\mathrm{C}, 71.76 ; \mathrm{H}, 7.21 ; \mathrm{N}, 6.28 \%$.

The syntheses of 4-heptyloxyaniline and 4heptyloxyacetanilide were described above. Hexakis(4-formylphenoxy)cyclotetraphosphazene was synthesized from 4-hydroxybenzaldehyde (17.5 g, $0.143 \mathrm{~mol}), \mathrm{NaH}(5.73 \mathrm{~g}, 0.143 \mathrm{~mol})$ and hexachlorocyclotetraphosphazene $(5.0 \mathrm{~g}, 10.6 \mathrm{mmol})$ in THF $(125 \mathrm{ml})$ under reflux for $2 \mathrm{~h}$. The crude products were purified by reprecipitation in hexane after being dissolved in a small amount of THF. The product was confirmed by TLC (1:1 ethyl acetate chloroform) and ${ }^{1} \mathrm{H}$ and ${ }^{31} \mathrm{P}$ NMR.

Octakis $\left\{\left[4-\left[N-\left(4^{\prime}\right.\right.\right.\right.$-heptyloxyphenyl $)$ iminomethyl]phenoxy]\} cyclotetraphosphazene (OHICP) was prepared by the reaction of hexakis(4-formylphenoxy)cyclotetraphosphazene $(1.0 \mathrm{~g}, 0.87 \mathrm{mmol})$ and 4-heptyloxyaniline $(2.7 \mathrm{~g}, 13 \mathrm{mmol})$ in benzene $(50 \mathrm{ml})$ under reflux for $6 \mathrm{~h}$. Water present in the solution was removed by the molecular sieves in the Dean-Stark tube. The crude products obtained were recrystallized three times from benzene and once from 1:1 THF cyclohexane after being separated by filtration. The products were characterized by ${ }^{1} \mathrm{H}$ and ${ }^{31} \mathrm{P}$ NMR. The analytical results for OHICP were as follows: m.p. $425 \mathrm{~K}$; IR (KBr) 2933, 2858, 1604, 1578, 1251, 1219, 1161, $983 \mathrm{~cm}^{-1} ;{ }^{1} \mathrm{H}$ NMR $\left(\mathrm{CDCl}_{3}\right) \delta 1.1(\mathrm{t}, 7.3 \mathrm{~Hz}, 3 H)$, 1.3-1.8 (m, 10H), $3.9(\mathrm{t}, 7.3 \mathrm{~Hz}, 2 H), 6.8(\mathrm{~d}, 8.8 \mathrm{~Hz}$, $2 H), 7.0(\mathrm{~d}, 8.8 \mathrm{~Hz}, 2 H), 7.3$ (d, 8.4 Hz, 2H), 8.4 (s, $1 H) ;{ }^{31} \mathrm{P}$ NMR $\delta-12.7(\mathrm{~s})$.

\section{Synthesis of a cyclotriphosphazene with an optically active alkoxybiphenyl moiety}

$(S)$-Hexakis $\left\{\left[4-\left[4^{\prime}-6\right.\right.\right.$-methyl)octyloxy]biphenoxy] \} cyclotriphosphazene (SMOCP) was synthesized using the following procedure. $(S)$-1-Chloro2-methylbutane $(\mathrm{SCMB})\left([\alpha]^{25}=-4.6^{\circ}\right)$ was prepared from $(S)$-2-methylbutanol $(41 \mathrm{~g}, 0.47 \mathrm{~mol}$, $[\alpha]^{25}=-5.8^{\circ}$ ) according to the described procedures. ${ }^{19}$ A suspension of 1,4-dibromoethane (26 g, $0.12 \mathrm{~mol})$ and dilithium tetrachlorocuprate $(0.42 \mathrm{~g}$, $1.9 \mathrm{mmol})$ in THF $(100 \mathrm{ml})$ was added to the Grignard reagent prepared from SCMB (20 g, $0.19 \mathrm{~mol})$ and $\mathrm{Mg}(4.6 \mathrm{~g}, 0.19 \mathrm{~mol})$ in diethyl ether $(100 \mathrm{ml}) .^{20-23}$ The dilithium tetrachlorocuprate was obtained by the reaction of lithium chloride $(0.16 \mathrm{~g}$, $3.8 \mathrm{mmol})$ and cupric chloride $(0.26 \mathrm{~g}, 1.9 \mathrm{mmol})$ in THF (40 ml). The mixture was gradually warmed to ambient temperature over the course of $4 \mathrm{~h}$ with stirring. After a further $24 \mathrm{~h}$, distillation of the crude product under $8 \mathrm{mmHg}$ gave $12.3 \mathrm{~g}$ of (S)-1-bromo-6-methyloctane (SBM) with $[\alpha]^{25}=$ $+7.7^{\circ} \mathrm{C}$. (S)-4-(6-Methyloctyloxy)biphenyl-4'-ol (SMBO) was prepared by heating a mixture of SBM (12 g, $58 \mathrm{mmol}), 44^{\prime}$-dihydroxybiphenyl $(16 \mathrm{~g}, 87 \mathrm{mmol})$ and potassium hydroxide $(5.9 \mathrm{~g}$, 
$90 \mathrm{mmol})$ in ethanol $(500 \mathrm{ml})$ under reflux for $8 \mathrm{~h}$. The crude product, when filtered using hot toluene, crystallized out from the filtrate upon cooling to room temperature. The crystals obtained were purified by column chromatography $\left(\mathrm{CHCl}_{3}\right)$, followed by recrystallization from hexane; m.p. $405 \mathrm{~K},[\alpha]^{25}=+7.3^{\circ}$.

The sodium salt of $\mathrm{SMBO}(10 \mathrm{~g}, 32 \mathrm{mmol})$, prepared by treating with $\mathrm{NaH}(1.4 \mathrm{~g}, 35 \mathrm{mmol})$ in dioxane $(25 \mathrm{ml})$, was mixed with hexachlorocyclotriphosphazene (HCCP) (1.6 g, $4.4 \mathrm{mmol})$ and tetra-n-butylammonium bromide $(1.0 \mathrm{~g}, 3.2 \mathrm{mmol})$ in dioxane $(45 \mathrm{ml})$. The solution was heated under reflux for $24 \mathrm{~h}$. The crude SMOCP product was subjected to column chromatography $\left(\mathrm{CHCl}_{3}\right)$ and recrystallized from hexane/THF $(20: 1)$. The analytical results for SMOCP were as follows: m.p. $418 \mathrm{~K}$, c.p. $441 \mathrm{~K} ;[\alpha]^{27}=+5.9^{\circ}$ (c 1.0 , $\mathrm{CHCl}_{3}$ ); IR (KBr): 2930, 1608-1497, 1249, 1166, $963,730 \mathrm{~cm}^{-1}$; ${ }^{1} \mathrm{H}$ NMR $\left(\mathrm{CDCl}_{3}\right) \delta 0.9(\mathrm{~m}, 6 H)$, $1.1-1.5(\mathrm{~m}, 9 H), 1.8(\mathrm{~m}, 2 H), 4.0(\mathrm{t}, 6.6 \mathrm{~Hz}, 2 H)$, $6.8(\mathrm{~d}, 8.4 \mathrm{~Hz}, 2 H), 6.9(\mathrm{~d}, 8.4 \mathrm{~Hz}, 2 H), 7.2(\mathrm{~d}$, $8.8 \mathrm{~Hz}, 2 H), 7.4(\mathrm{~d}, 8.4 \mathrm{~Hz}, 2 H) ;{ }^{31} \mathrm{P}$ NMR $\delta 10.6$ (s). Analysis: Calcd for $\mathrm{C}_{126} \mathrm{H}_{162} \mathrm{~N}_{3} \mathrm{O}_{12} \mathrm{P}_{3}$ : C, 75.53; H, 8.15; N, 2.10; found: C, 75.83; H, 8.30; $\mathrm{N}, 2.10 \%$.

1-Bromo-6-methyloctane (MO) was prepared from the Grignard reagent from 1-chloro-2-methylbutane, and 1,4-dibromoethane, in the presence of dilithium tetrachlorocuprate in THF solution. 4-(6Methyloctyloxy)biphenyl-4'-ol (MOBP) was synthesized from MO and 4,4'-dihydroxybiphenyl. The racemic mixture of hexakis $\left\{\left[4-\left[4^{\prime}-6-m e t h y l\right)-\right.\right.$ octyloxy]biphenoxy]\} cyclotriphosphazene (MOCP) was prepared from HCCP and MOBP using a method similar to that for SMOCP and judged to be thoroughly purified by the same method.

\section{Analytical techniques and instruments}

Phase transition temperatures were measured using a differential scanning calorimeter (Seiko Electronics DSC 210) and texture observations were performed using an optical polarizing microscope (Nikon Optiphot-pol XTP-11) equipped with a Mettler FP 82 hot stage at a heating/cooling rate of $5 \mathrm{~K} \mathrm{~min}^{-1}$ from room temperature up to above the melting or clearing point. ${ }^{1} \mathrm{H} \mathrm{NMR}$ ( solvent $\mathrm{CDCl}_{3}$ ) and ${ }^{31} \mathrm{P}$ NMR (solvent THF) were recorded on a JEOL JNM-GX 270 spectrometer using TMS as the internal standard for the former and $85 \% \mathrm{H}_{3} \mathrm{PO}_{4}$ as the external standard for the latter. The lock signal for ${ }^{31} \mathrm{P}$ NMR was provided by external $\mathrm{D}_{2} \mathrm{O}$ inserts.
The optical purity of the chiral compounds was determined by measurement of optical rotatory power, using an atomic digital polarizer (Otsuka Electronics Co. Ltd; PM-201A). Spontaneous polarization was measured by the triangular-wave method $^{24,25}$ using a wave-function generator (NF Electronic Instruments, 1920A) and an amplifier (NF Electronic Instruments, 4005) and simultaneously observing the texture of the sample with a polarizing microscope (Nikon Optiphot-pol XTP11) by cooling from an isotropic liquid at a rate of $0.1 \mathrm{~K} \mathrm{~min}^{-1}$. The triangular wave applied was $1 \mathrm{~Hz}$ and $150 \mathrm{~V}$. Signals of the samples were read by a digital oscilloscope (Hitachi VC-6020) and transferred to a microcomputer (NEC, PC9801). The apparatus was calibrated by measuring the spontaneous polarization of $(S)$-2-methylbutyl 4-(4'-decyloxybenzylidenamino)cinnamate (DOBAMBC). The spontaneous polarization for DOBAMBC is $8.15 \mu \mathrm{C} \mathrm{m}^{-2}$ at $362 \mathrm{~K}$, which is consistent with the value in the literature. ${ }^{26,27}$ The measurements were performed on a 1.4, 3.7, 12 and $25 \mu \mathrm{m}$-thick antiparallel-oriented liquid-crystalline cell, whose sample area is confined to $20 \mathrm{~mm}^{2}$ by etching the ITO-coated glass surfaces. The antiparallel orientation $^{28-30}$ was obtained by rubbing with a velvet cloth using a handmade rubbing machine after coating with polyimide, PSI-A-X044-CF1 (Chisso Petrochemical Co.). For an accurate calculation of the spontaneous polarizations of the SMOCP, a separately synthesized racemic mixture of MOCP was used as the base line of the signal. The tilt angles were measured by the angles between the two distinction positions, which are determined by applying a DC electric field of sufficient strength to release the helix of the ferroelectric liquid crystals in the smectic $C^{*}$ layer perpendicular to the substrate liquid-crystalline cells.

\section{RESULTS AND DISCUSSION}

\section{Mesogenicity of organophosphazenes with a 4- octyloxybiphenoxy moiety}

In this section hexakis [4'-(4-octyloxy)biphenoxy]cyclotriphosphazene (HOCP), octakis [4'-(4-octyloxy)biphenoxy]cyclotetraphosphazene (OOCP) and poly\{bis[4'-(4-octyloxy)biphenoxy]phosphazene (POP) will be described.

DSC thermograms of HOCP and OOCP for the first cooling process and the second heating process 


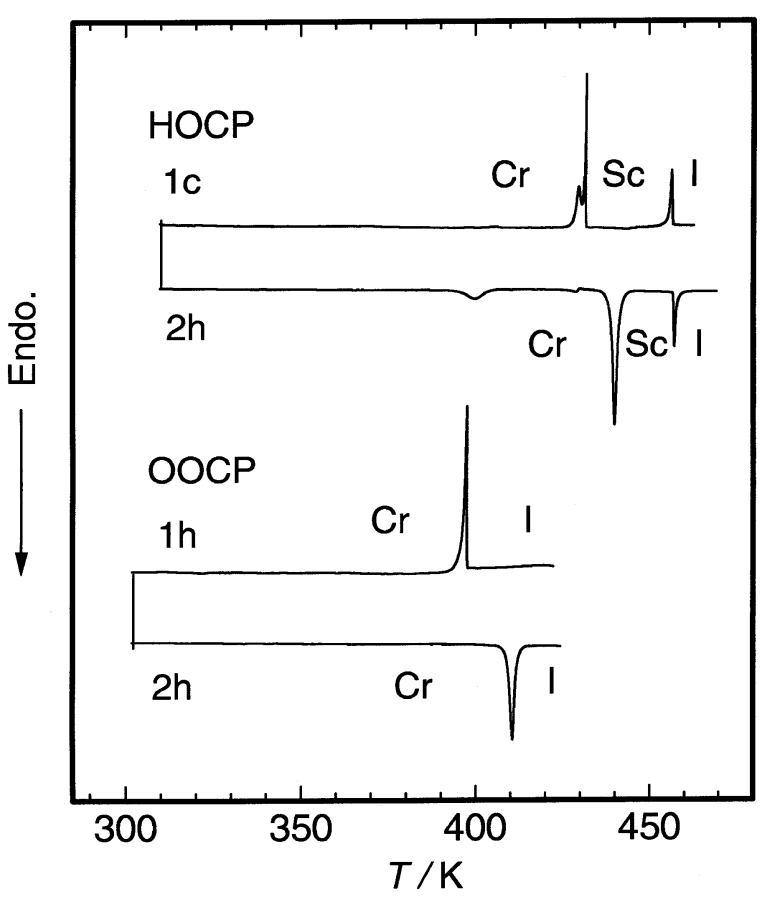

Figure 2 DSC thermograms of hexakis [4'-(4-octyloxy)biphenoxy]cyclotriphosphazene (HOCP) and octakis [4'-(4-octyloxy)biphenoxy]cyclotetraphosphazene (OOCP).

are shown in Fig. 2. In the first HOCP cooling process, three exothermic peaks are seen at 457 , 432 and $430 \mathrm{~K}$. In the second heating process, three endothermic peaks are seen at 400,440 and $457 \mathrm{~K}$. From the polarizing microscope observations, a schlieren texture with disclination lines having $s= \pm 1$ and a simultaneous broken-fan texture was observed between 457 and $432 \mathrm{~K}$ upon cooling from an isotropic liquid. This texture shows the existence of a smectic $\mathrm{C}$ phase. ${ }^{31}$ The thermal anomalies at $430 \mathrm{~K}$ in the first cooling process and at $400 \mathrm{~K}$ in the second heating process may correspond to crystal -crystal phase transitions because no other mesogenic texture was observed in the polarizing microscope observations in these temperature regions. In the DSC thermograms of OOCP, only one exothermic peak, which corresponds to the phase transition from an isotropic liquid (I) to crystal $(\mathrm{Cr}$ ), was observed at $397 \mathrm{~K}$ for the first cooling process. In the second heating process, only one endothermic peak, which corresponds to the $\mathrm{Cr}-\mathrm{I}$ phase transition, was observed at $411 \mathrm{~K}$. Using polarizing microscopy, no liquidcrystalline phase was observed for OOCP. The thermodynamic parameters of HOCP and OOCP obtained from the second heating process of the DSC measurements are shown in Table 1. It is found from Table 1 that the disorder of the SmC phase in HOCP is much closer to that in the isotropic liquid than to that in the crystal because the entropy change of the SmC-I phase transition $\left(\Delta S_{\mathrm{SmC}}-\mathrm{I}\right)$ is much smaller than the melting entropy $\left(\Delta S_{\mathrm{m}}\right)$ of HOCP.

In the X-ray single-crystal structure analysis of hexakis(4-biphenoxy)cyclotriphosphazene (HBCP) and octakis(4-biphenoxy)cyclotetraphosphazene $(\mathrm{OBCP})$, the side-chains line up relatively regularly for the former and randomly for the latter. ${ }^{32}$ The molecular structure of the HOCP under the assumption of a similar situation in HBCP is shown in Fig. 3. The results of the mesogenic properties in HOCP and OOCP were interpreted as follows. The molecular organization of HOCP (trimer) helps the formation of the smectic layer structure because the ordering of the side-chains in HOCP increases the aspect ratio (the ratio of the molecular long axis to the short axis) of the molecule. However, the random orientation of the side chains in OOCP (tetramer) prevents the formation of the smectic layer structure.

For the polyphosphazenes with a similar alkoxybiphenyl moiety (POP), only $66 \%$ of the sidechains were introduced in the 160 h-reaction sample, which was determined by elementary analysis. No liquid-crystalline phase transition in POP was observed by polarizing microscopy. This result suggests that the fully substituted poly-

Table 1 Thermodynamic parameters of hexakis [4'-(4-octyloxy)biphenoxy]cyclotriphosphazene (HOCP) and octakis [4'-(4octyloxy)biphenoxy]cyclotetraphosphazene (OOCP) in the second heating process

\begin{tabular}{lcccc}
\hline \multirow{2}{*}{ Compound } & $T_{\mathrm{m}}$ & $\frac{\Delta S_{\mathrm{m}}}{\mathrm{K}}$ & $\frac{T_{\text {SmC-I }}}{\mathrm{JK}} \mathrm{mol}^{-1}$ & $\frac{\Delta S_{\text {SmC-I }}}{\mathrm{JK}^{-1} \mathrm{~mol}^{-1}}$ \\
\hline HOCP & 440 & 184 & 457 & 33 \\
OOCP & 411 & 185 & & \\
\hline
\end{tabular}

$T_{\mathrm{m}}$; melting temperature, $\Delta S_{\mathrm{m}}$; melting entropy, $T_{\mathrm{SmC-I}}$; transition temperature from SmC to isotropic liquid, $\Delta S_{\mathrm{SmC-I}}$; transition entropy from $\mathrm{SmC}$ to isotropic liquid. 


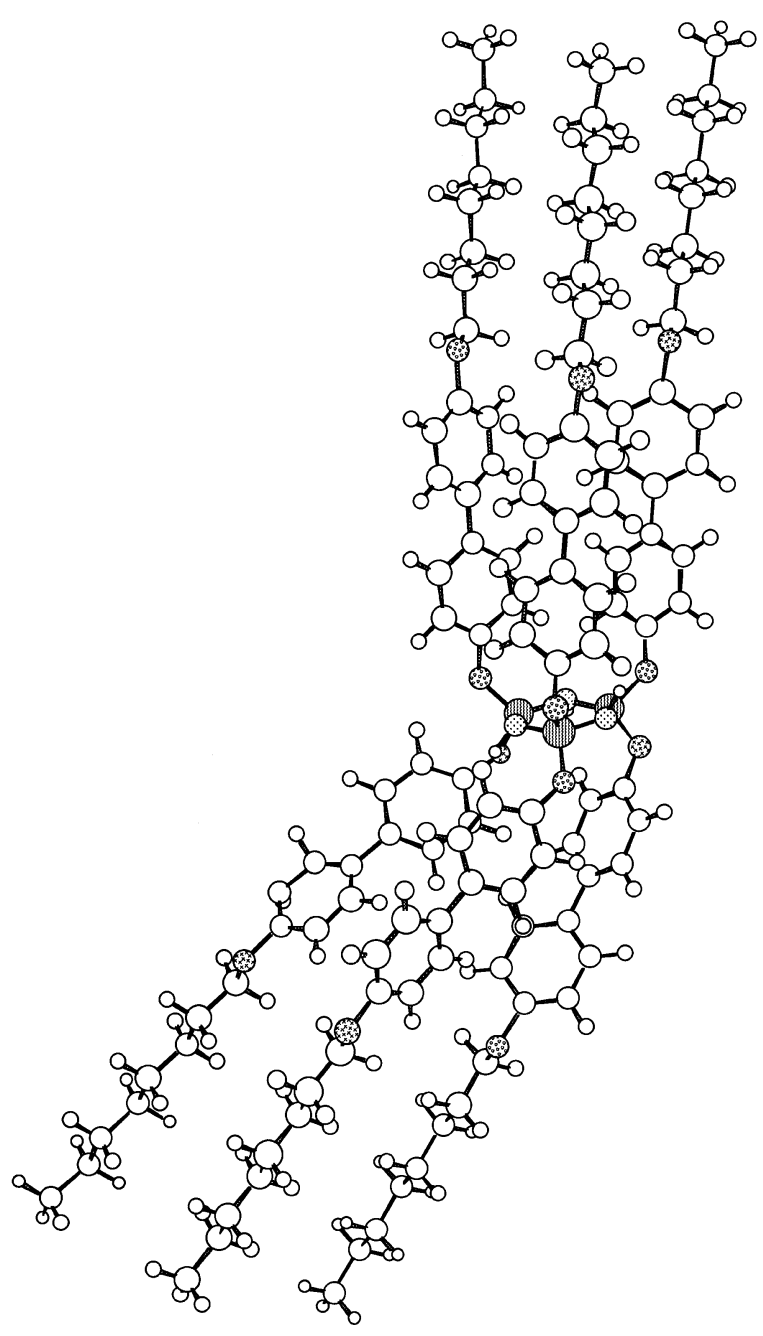

Figure 3 Assumed molecular structure of HOCP.

phosphazene with 4-octyloxybiphenyl side-groups cannot be prepared at atmospheric pressure and at the boiling temperature of THF.

\section{Mesogenicity of organophoaphazenes with a Schiff base moiety}

The DSC thermograms of hexakis $\left\{4-\left[N-\left(4^{\prime}-\right.\right.\right.$ heptyloxyphenyl)iminomethyl]phenoxy $\}$ cyclotriphosphazene (HHICP) (trimer) and octakis $\left\{4-\left[N-\left(4^{\prime}-\right.\right.\right.$ heptyloxyphenyl)iminomethyl]phenoxy $\}$ cyclotetraphosphazene (OHICP) (tetramer) are shown in Fig. 4. In the first HHICP cooling process, two large and two small exothermic peaks are seen at 514 and $457 \mathrm{~K}$, and at 503 and $486 \mathrm{~K}$, respectively. From

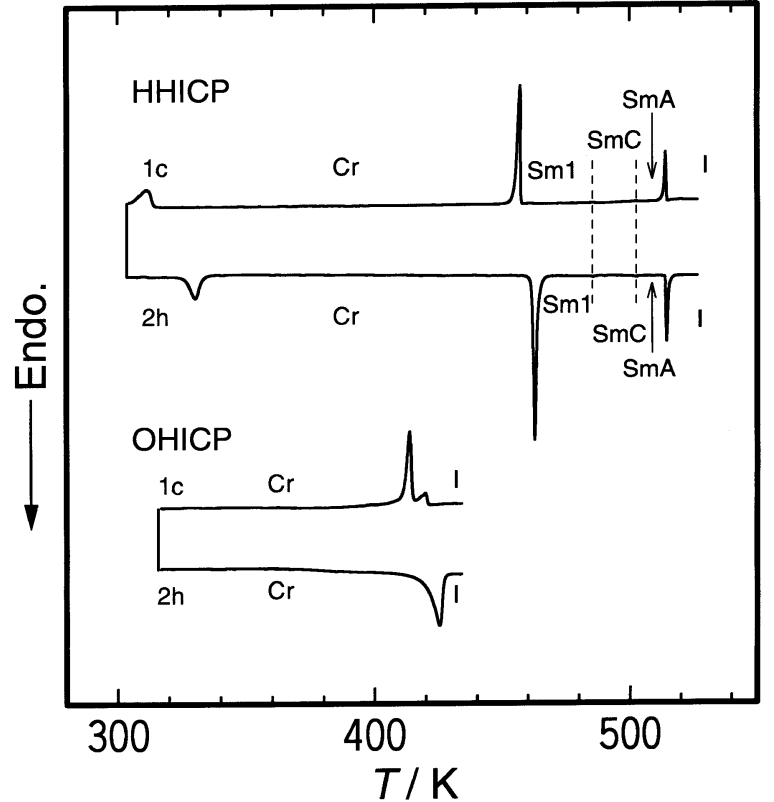

Figure 4 DSC thermograms of hexakis $\left\{4-\left[N-\left(4^{\prime}\right.\right.\right.$-heptyloxyphenyl)iminomethyl]phenoxy cyclotriphosphazene (HHICP) and octakis $\left\{4-\left[N-\left(4^{\prime}\right.\right.\right.$-heptyloxyphenyl)iminomethyl]phenoxy $\}$ cyclotetraphosphazene (OHICP).

the polarizing microscope observations, the peaks at 514 and $457 \mathrm{~K}$ correspond to the clearing and freezing point. Upon cooling from an isotropic liquid, an SmA phase with fan and black (homeotropic) textures was observed at $514 \mathrm{~K}$. Below $503 \mathrm{~K}$, the fan and black textures changed to broken-fan and simultaneous schlieren texture with disclination lines having $s= \pm 1$, showing the presence of the SmC. Below $486 \mathrm{~K}$, the schlieren texture changed to a mosaic one during the cooling process. This phase is a more ordered smectic phase than that of smectic $\mathrm{C}$ but was not determined. For the identification of this phase, a more precise experiment, e.g. a mixing test with a liquid crystal of known phases will be needed. At $457 \mathrm{~K}$, the mesomorphic phase changed to a crystal. In the second HHICP heating process (Fig. 4), five endothermic peaks are seen in the DSC thermograms at $330,463,486,503$ and $515 \mathrm{~K}$. The endothermic peaks at 463 and $515 \mathrm{~K}$ from the polarizing microscope observations correspond to melting and clearing points, respectively. The small peaks at 486 and $503 \mathrm{~K}$ are considered to correspond to the Sm1-SmC and SmC-SmA phase transitions because the phase-transition temperatures and phase-transition entropies are similar to 
Table 2 The thermodynamic parameters of hexakis $\{4-[N$-(4'-heptyloxyphenyl)iminomethyl]phenoxy $\}$ cyclotriphosphazene (HHICP) and octakis $\left\{4-\left[N-\left(4^{\prime}\right.\right.\right.$-heptyloxyphenyl)iminomethyl]phenoxy $\}$ cyclotetraphosphazene (OHICP) in the second heating process

\begin{tabular}{|c|c|c|c|c|c|c|c|c|}
\hline Compound & $\frac{T_{\mathrm{m}}}{\mathrm{K}}$ & $\frac{\Delta S_{\mathrm{m}}}{\mathrm{JK}^{-1} \mathrm{~mol}^{-1}}$ & $\frac{T_{\mathrm{S} 1-\mathrm{SmC}}}{\mathrm{K}}$ & $\frac{\Delta S_{\mathrm{S} 1-\mathrm{SmC}}}{\mathrm{JK}^{-1} \mathrm{~mol}^{-1}}$ & $\frac{T_{\mathrm{SmC}-\mathrm{SmA}}}{\mathrm{K}}$ & $\frac{\Delta S_{\text {SmC-SmA }}}{\mathrm{JK}^{-1} \mathrm{~mol}^{-1}}$ & $\frac{T_{\text {SmA-I }}}{\mathrm{K}}$ & $\frac{\Delta S_{\text {SmA-I }}}{\mathrm{JK}^{-1} \mathrm{~mol}^{-1}}$ \\
\hline HHICP & 463 & 166 & 486 & 0.7 & 503 & 0.4 & 515 & 33 \\
\hline
\end{tabular}

$T_{\mathrm{m}}$; melting temperature, $\Delta S_{\mathrm{m}}$; melting entropy, $T_{\mathrm{S} 1-\mathrm{SmC}} ; \mathrm{S} 1-\mathrm{SmC}$ transition temperature, $\Delta S_{\mathrm{S} 1-\mathrm{SmC}} ; \mathrm{S} 1-\mathrm{SmC}$ transition entropy, $T_{\mathrm{SmC-SmA}}$; SmC-SmA transition temperature, $\Delta S_{\mathrm{SmC}-\mathrm{SmA}}$; SmC-SmA transition entropy, $T_{\mathrm{SmA-I}}$; transition temperature from SmA to isotropic liquid, $\Delta S_{\mathrm{SmA-I}}$; transition entropy from $\mathrm{SmA}$ to isotropic liquid.

those of the first cooling process. The thermodynamic parameters obtained from DSC measurements of the second heating process are shown in Table 2 along with those of the tetrameric derivative (OHICP). The low entropies of the Sm1-SmC and SmC-SmA phase transitions suggest that the structures of the Sm1, SmC and SmA phases are very close together.

In the first cooling process in the DSC thermograms of OHICP (Fig. 4), two exothermic peaks are seen around 420 and $414 \mathrm{~K}$. Between the two exothermic peaks, the existence of a mesomorphic phase can be expected. However, the polarizing microscope observation did not reveal a clear mesomorphic texture. In the second OHICP heating process, only one endothermic phase corresponding to melting is seen at $425 \mathrm{~K}$; in addition, no mesomorphic phase was observed by polarizing microscopy.

\section{Mesogenicity of a cyclotriphosphazene with an optically active moiety}

A chiral moiety was introduced into the alkoxy groups of the side-chains and their mesogenicity was studied. The DSC thermograms of $(S)$-hexakis $\left\{4-\left[4^{\prime}-(6-\right.\right.$ methyl)octyloxy]biphenoxy $\}$ cyclotriphosphazene (SMOCP) (trimer) are shown in Fig. 5. In the first SMOCP cooling process, three exothermic peaks were observed at 440, 403 and $352 \mathrm{~K}$. Polarizing microscopy showed a shlieren texture with disclination lines having $s= \pm 1$ and a simultaneous broken-fan texture with a stripe between 440 and $403 \mathrm{~K}$. This demonstrates the existence of a smectic $C^{*}$ phase. The SMOCP changed to a crystal at $403 \mathrm{~K}$ on the polarizing microscope. In the second heating of SMOCP, three endothermic peaks were observed at 410,418 and $441 \mathrm{~K}$. From the polarizing microscope observation, the peak at $418 \mathrm{~K}$ corresponds to the melting point. The thermodynamic parameters of SMOCP obtained from the second heating process $b$, DSC measurements are shown in Table 3 . The first-order nature of the phase transition is detected by the DSC measurements in which the entropy of the SmC-I phase transition is relatively large $(\Delta S \simeq$ $\left.28 \mathrm{JK}^{-1} \mathrm{~mol}^{-1}\right)$. The values of the transition entropy are much larger than those of the usual liquid crystals, consisting of rigid central groups and flexible end-groups.

The width of the stripe in the broken-fan texture in the homogeneous cell, in which the smectic layer is almost perpendicular to the glass slide, shows helical pitches in the $\mathrm{Sc}^{*}$ phase. The helical pitches are about $12 \mu \mathrm{m}$ at $436 \mathrm{~K}$. This large value suggests that the twisting power of SMOCP in the Sc* phase is relatively small. The dependence of the liquidcrystalline cell thickness on the spontaneous polarization observed for the cell thicknesses of $1.4,3.7,12$ and $25 \mu \mathrm{m}$ is seen in Fig. 6 in which $T_{\mathrm{c}}$ is $440 \mathrm{~K}$. The spontaneous polarization is -71 , $-110,-150$ and $-190 \mu \mathrm{C} \mathrm{m}^{-2}$ for cell thicknesses

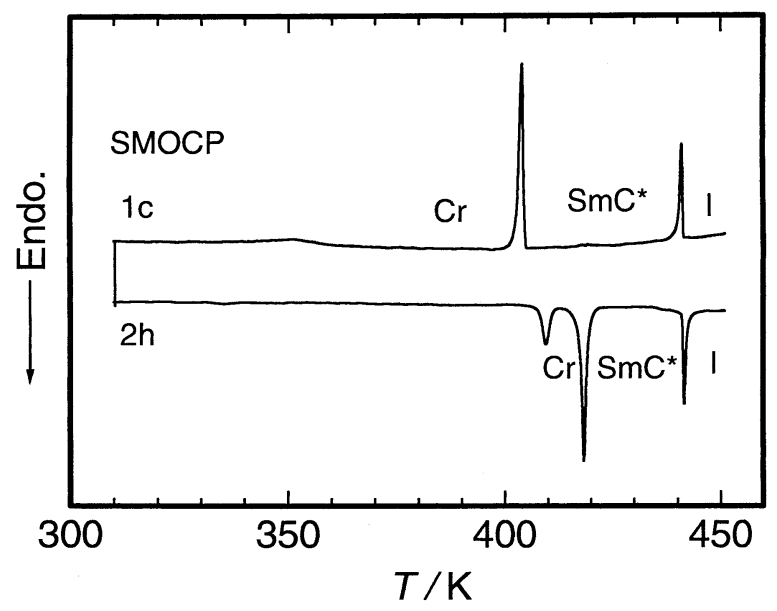

Figure 5 DSC thermograms of $(S)$-hexakis $\left\{4-\left[4^{\prime}\right.\right.$-(6-methyl)octyloxy]biphenoxy\}cyclotriphosphazene (SMOCP). 
Table 3 The thermodynamic parameters of hexakis $\left\{4-\left[4^{\prime}-((S) 6\right.\right.$-methyl)octyloxy]biphenoxy $\}$ cyclotriphosphazene (SMOCP) in the second heating process

\begin{tabular}{lcccc}
\hline Compound & $\frac{T_{\mathrm{m}}}{\mathrm{K}}$ & $\frac{\Delta S_{\mathrm{m}}}{\mathrm{JK}^{-1} \mathrm{~mol}^{-1}}$ & $\frac{T_{\text {SmC-I }}}{\mathrm{K}}$ & $\frac{\Delta S_{\text {SmC-I }}}{\mathrm{JK}^{-1} \mathrm{~mol}^{-1}}$ \\
\hline SMOCP & 418 & 80 & 441 & 29 \\
\hline
\end{tabular}

$T_{\mathrm{m}}$; melting temperature, $\Delta S_{\mathrm{m}}$; entropy of melting, $T_{\mathrm{SmC}-\mathrm{I}}$; transition temperature from SmC to isotropic liquid, $\Delta S_{\mathrm{SmC-I}}$; transition entropy from $\mathrm{SmC}$ to isotropic liquid.

of $1.4,3.7,12$ and $25 \mu \mathrm{m}$ respectively, at $436 \mathrm{~K}$. These values are several times larger than that of (S)-2-methylbutyl 4-(4'-decyloxybenzylidene)aminocinnamate (DOBAMBC). These relatively large values may be caused by the ether linkage of the alkoxy end-groups. The spontaneous polarization decreased with a decrease in the thickness of liquid crystalline cells. This is due to the cell surface effect at the interface between the liquid-crystalline cell (polyimide) and the liquid crystal (SMOCP). The surface effect seems to increase with decreasing cell thickness. For a $25 \mu \mathrm{m}$ cell, decreasing temperature causes a spontaneous polarization increase and shows a maximum around $T_{\mathrm{c}^{-}}$ $T=2.5 \mathrm{~K}$. The maximum of the spontaneous polarization decreases slightly to lower temperature with decreasing cell thickness. The temperature dependences of the tilt angles are shown in Fig. 7. The tilt angle is ca $25^{\circ}$ at $T_{\mathrm{c}}$ and increases with decreasing temperature. These results show that the phase transition of the isotropic liquid-Sc* phase

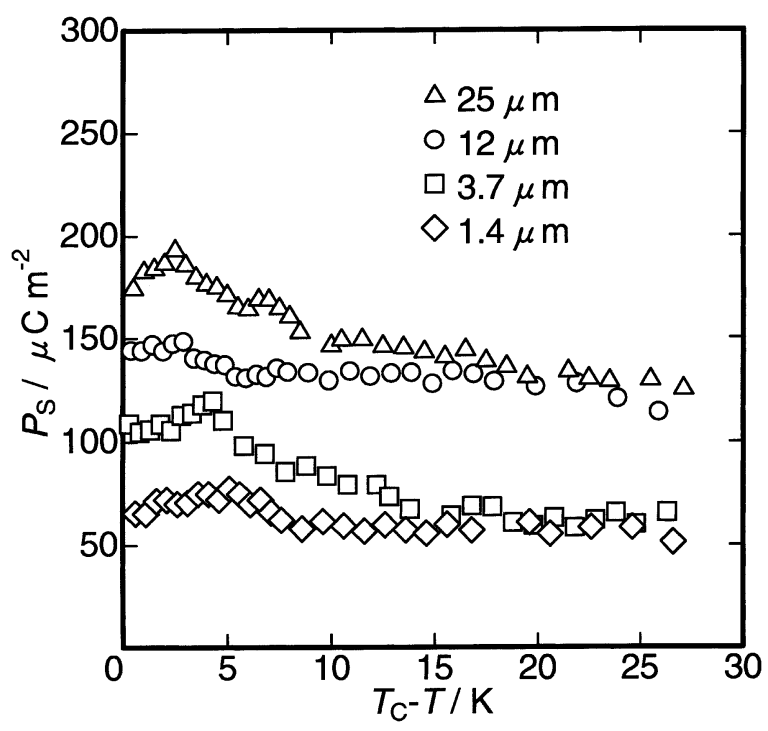

Figure 6 Dependence of cell thickness on the spontaneous polarization of $\mathrm{Sc}^{*}$ in $\mathrm{SMOCP}$.

(C) 1998 John Wiley \& Sons, Ltd. has a first-order characteristic. The tilt angle becomes $28^{\circ}$ around $T-T_{\mathrm{c}}=6 \mathrm{~K}$ and shows only a slight increase below this temperature.

\section{CONCLUSIONS}

Liquid crystalline phase transitions were studied using DSC measurements and polarizing microscopy. All cyclotriphosphazenes showed clear smectic phases. Interestingly, cyclotriphosphazene with an optically active side-group displayed a ferroelectric liquid-crystalline phase $\left(\mathrm{Sc}^{*}\right)$ with a spontaneous polarization. On the other hand, the corresponding cyclotetraphosphazenes did not show a mesomorphic phase. From this result we can postulate that, in the cyclotriphosphazenes, each half of the mesogenic side-groups should extend perpendicularly upwards and downwards to the cyclotriphosphazene ring plane to facilitate the formation of the layer structure as in hexakis(4biphenoxy)cyclotriphosphazene. ${ }^{14}$ The origin of the smectic architecture in the liquid-crystalline

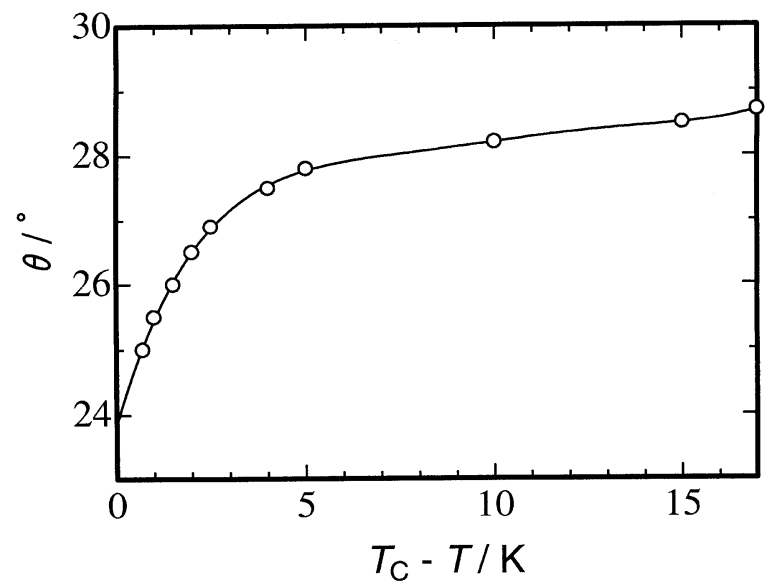

Figure 7 Temperature dependence on the tilt angle in the Sc* phase of SMOCP.

Appl. Organometal. Chem. 12, 771-779 (1998) 
phase is then attributable to these specific molecular frameworks. In contrast, in the cyclotetraphosphazenes the side-chains point in relatively random directions, thus preventing the formation of the layer structure. In the polymers, which are not fully substituted, no mesomorphic phase was observed. The polymer backbone of the polyphosphazenes may prevent the formation of the liquid-crystalline phase.

Acknowledgment We thank Nihon Soda Co. Ltd, the Japan Fine Chemicals, Co. Ltd and the Chisso Petrochemicals Co. for providing us with octachlorocyclotetraphosphazene, hexachlorocyclotriphosphazene and polyimide A-X044-CF1, respectively. We also express our thanks to Professors Hideo Takezoe and Yoichi Takanishi of the Tokyo Institute of Technology for teaching us the triangular-wave method techniques and for fruitful discussions.

\section{REFERENCES}

1. H. R. Allcock, Chem. Rev. 72, 319 (1972).

2. H. R. Allcock, in: Phosphorus-Nitrogen Compounds, Academic Press, New York, 1972.

3. H. G. Heal, in: The Inorganic Heterocyclic Chemistry of Sulphur, Nitrogen and Phosphorus, Academic Press, New York, 1980, p. 214.

4. C. W. Allen, in: The Chemistry of Inorganic Homo- and Heterocycles, Vol. 2, Haiduc, I. and Sowerby, D. B. (eds), Academic Press, New York, 1987, p. 501.

5. C. W. Allen, Organophosphorus Chem. 21, 368 (1990).

6. C. Kim and H. R. Allcock, Macromolecules 20, 1726 (1987).

7. R. E. Singler, R. A. Willingham, R. W. Lenz, A. Furukawa and H. Finkellmann, Macromolecules 20, 1727 (1987).

8. H. R. Allcock and C. Kim, Macromolecules 22, 2596 (1989).

9. H. R. Allcock C. and C. Kim, Macromolecules 23, 3881 (1990).

10. H. R. Allcock and E. H. Klingenberg, Macromolecules 28, 4351 (1995).
11. K. Moriya, S. Yano and M. Kajiwara, Chem. Lett. 1039 (1990).

12. K. Moriya, S. Miyata, S. Yano and M. Kajiwara, J. Inorg. Organomet. Polym. 2, 443 (1992).

13. K. Moriya, H. Mizusaki, M. Kato, S. Yano and M. Kajiwara, Liq. Cryst. 18, 795 (1995).

14. K. Moriya, S. Nakagawa, S. Yano and M. Kajiwara, Liq. Cryst. 18, 919 (1995).

15. K. Moriya, T. Suzuki, S. Yano and M. Kajiwara, Liq. Cryst. 19, 711 (1995).

16. A. M. Levelut and K. Moriya, Liq. Cryst. 20, 119 (1996).

17. K. Moriya, H. Mizusaki, M. Kato, T. Suzuki, S. Yano, M. Kajiwara and K. Tashiro, Chem. Mater. 9, 255 (1997).

18. K. Moriya, T. Suzuki, H. Mizusaki, S. Yano and M. Kajiwara, Chem. Lett. 1001 (1997)

19. W. T. Bailey and E. T. Yates, J. Org. Chem. 26, 3193 (1961).

20. B. Otterholm, M. Nilsson, S. T. Lagerwall and K. Skarp, Liq. Cryst. 2, 757 (1987).

21. S. M. Kelly and K. Buchecker, Helv. Chim. Acta 71, 451 (1988).

22. L. Friedman and A. Shani, J. Am. Chem. Soc. 96, 7101 (1974).

23. M. Tamara and T. Kochi, Synthesis 303 (1971).

24. K. Miyasato, S. Abe, H. Takezoe, A. Fukuda and E. Kuze, Jap. J. Appl. Phys. 22, L661 (1983).

25. H. Takezoe, K. Kondo, K. Miyasato, S. Abe, T. Tsuchiya, A. Fukuda and E. Kuze, Ferroelectrics 58, 55 (1984).

26. S. Dumrongrattana and C. C. Huang, Phys. Rev. Lett. 56, 464 (1986).

27. K. Kondo, H. Takezoe, A. Furukawa and E. Kuze, Jpn. J. Appl. Phys. 22, L85 (1985).

28. K. Ishikawa, K. Hashimoto, H. Takezoe, A. Fukuda and E. Kuze, Jpn. J. Appl. Phys. 23, L211 (1984).

29. K. Ishikawa, Y. Ouchi, T. Uemura, T. Tsuchiya, H. Takezoe and A. Fukuda, Mol. Cryst. Liq. Cryst. 122, 175 (1985).

30. T. Hatano, K. Yamamoto, H. Takezoe and A. Fukuda, Jpn. J. Appl. Phys. 25, 1762 (1986).

31. D. Demus and D. Richter, in: Textures of Liquid Crystals, Verlag Chemie, Weinheim, 1978, p. 32.

32. H. R. Allcock, D. C. Ngo, M. Parvez, R. R. Whittle and W. J. Birdsall, J. Am. Chem. Soc. 113, 2628 (1991). 